\title{
Tocotrienol alleviates inflammation and oxidative stress in a rat model of spinal cord injury via suppression of transforming growth factor- $\beta$
}

\author{
CHUANHUI XUN* ${ }^{*}$ MARDAN MAMAT* ${ }^{*}$, HAILONG GUO, PULAT MAMATI, JUN SHENG, \\ JIAN ZHANG, TAO XU, WEIDONG LIANG, RUI CAO and WEIBIN SHENG \\ Department of Spine Surgery, The First Affiliated Hospital of Xinjiang Medical University, \\ Urumqi, Xinjiang 830054, P.R. China
}

Received November 6, 2015; Accepted November 18, 2016

DOI: 10.3892/etm.2017.4505

\begin{abstract}
In recent years accumulating evidence has indicated that tocotrienol exhibits an oxidation resistance function, decreased cholesterol function, inhibits cancer function and has unique physiological functions, including anti-inflammatory, anti-apoptotic and anti-oxidative properties. The present study investigated the effect of tocotrienols on spinal cord injury (SCI) by evaluating oxidative stress, inflammation and inducible nitric oxide synthase (iNOS) in rats. A rat model of SCI was induced by operation. SCI rats were treated with $120 \mathrm{mg} / \mathrm{kg} /$ day tocotrienol once a day for eight consecutive weeks. Functional recovery following SCI was measured by using the Basso Beattie Bresnahan (BBB) locomotor rating scale. Then the volume of spinal cord contusions was measured following induction of SCI in the rats. In SCI rats, serum malondialdehyde, superoxide dismutase, catalase, glutathione peroxidase, nuclear factor- $\kappa$ B p65 unit, tumor necrosis factor- $\alpha$, interleukin (IL)-1 $\beta$ and IL-6 levels were analyzed using respective commercial immunoassay kits. Firstly, iNOS, transforming growth factor (TGF)- $\beta$, collagen type IV and fibronectin protein expression levels, in addition to iNOS activity and plasma nitric oxide (NO) production in SCI rats was analyzed using western blot analysis, commercial kits and Griess reagent, respectively. Tocotrienol treatment elevated BBB scores and contused volume in the SCI rats. Tocotrienol protected against SCI with reduced oxidative stress and inflammation, and inhibited iNOS protein
\end{abstract}

Correspondence to: Dr Weibin Sheng, Department of Spine Surgery, The First Affiliated Hospital of Xinjiang Medical University, 137 Liyushan South Road, Urumqi, Xinjiang 830054, P.R. China

E-mail: weibinsheng@yeah.net

*Contributed equally

Key words: tocotrienol, spinal cord injury, oxidative stress, inflammation, inducible nitric oxide synthase expression iNOS activity and plasma NO production in rats. In addition, treatment with tocotrienols suppressed TGF- $\beta$, collagen type IV and fibronectin protein expression levels in SCI rats. These results suggest that tocotrienols protect SCI, and suppress oxidative stress, inflammation and iNOS in this model of SCI through TGF- $\beta$, collagen type IV and fibronectin signaling pathways.

\section{Introduction}

Spinal cord injury (SCI) is a common type of motor system trauma which may cause varying degrees of four limbs or paraplegia with loss of labor ability, potentially resulting in a heavier burden on society and families in 2010 (1). Epidemiological data indicated that in the USA, traffic accidents and high-altitude falls were the predominant causes of SCI, accounting for $\sim 67.5 \%$. The majority of cases were in young men with an average age of 41.0 years, the annual average morbidity is $\sim 40$ per million people, and $\sim 12,000$ people per year and increasing (2). At present in the field of sports injury, recovery after SCI remains difficult. However, scholars worldwide continue to investigate new treatment strategies for SCI.

At present the SCI mechanism is divided into primary and secondary SCI (3). The former consists of instantaneous mechanical damage that is reversible. Secondary damage gradually forms in the weeks following primary damage, and is accompanied by a series of cell metabolism and gene expression changes, including excitatory amino acid release, free radical damage, decrease in ion inflow, inflammation and cell apoptosis, resulting in more harm than primary damage $(4,5)$. Numerous studies have shown that post changes of SCI gene expression play an important role in the pathological process $(4,5)$.

Transforming growth factor (TGF) $\beta$ is a multifunctional cytokine, and its function in mammals involves damage repair and the formation of scar tissue (6). The biological function of TGF- $\beta$ is mediated via the conduction of types I (RI) and II (RII) transmembrane receptors (7). TGF- $\beta$ is present in almost all cells; therefore, it can influence the physiological function of the majority of tissues correspondingly (8). In vitro, TGF- $\beta$ 
is a potent agent for astrocyte chemotaxis, which can result in the hypertrophy of astrocytes and upregulation of the synthesis of fibronectin and collagen IV (8).

Tocotrienols are isomers of vitamin E, located primarily in plants, with antioxidative (9), anti-tumor (10) and neuroprotective functions (11). Tocotrienols inhibit proliferation of breast cancer cells, show G1 phase retardation and can promote cell apoptosis $(12,13)$. However, to the best of our knowledge, the potential protective effect and underlying molecular mechanism of tocotrienol on SCI has not been investigated. In addition, investigated the hypothesis that the effect of tocotrienol on SCI is mediated via the suppression of TGF- $\beta$.

\section{Materials and methods}

Animals and surgery. A total of 45 female Sprague Dawley rats weighing 250-270 g were obtained from the Animal Resource Center of Xinjiang Medical University (Urumqi, China). Animal experiments were performed in accordance to the institutional guidelines provided by the Committee on Animal Research at Xinjiang Medical University.

Drugs and chemicals. Tocotrienol [D-(-Tocotrienol; purity, $>98 \%$ )] was purchased from Sigma-Aldrich (Merck KGaA, Darmstadt, Germany), shown in Fig. 1. Malondialdehyde (MDA), superoxide dismutase (SOD), catalase (CAT), activity of glutathione peroxidase (GSH-PX), NF- $\kappa$ B p65 unit, tumor necrosis factor (TNF)- $\alpha$, IL- $1 \beta$ and IL- 6 ELISA kits were purchased from R\&D Systems, Inc. (catalog nos. A003-1, A001-3, A007-2, A005, H202, H052, H002 and H007; Nanjing Jiancheng Bioengineering Institute, Nanjing, China). A bicinchoninic assay kit was bought from Beyotime Institute of Biotechnology (Nantong, China). Inducible nitric oxide synthase (iNOS) commercial kit was bought from Imgenex (catalog no. A014-1; Nanjing Jiancheng Bioengineering Institute).

Experimental groups and procedures. Sprague Dawley rats were randomly divided into four groups ( $n=10$ per group): i) Sham group, normal rats received physiological saline $0.1 \mathrm{ml} / 100 \mathrm{~g}$ (i.p.); ii) SCI group (SCI) (14), SCI model rats received physiological saline $0.1 \mathrm{ml} / 100 \mathrm{~g}$ (i.p.); iii) methylprednisolone sodium succinate (MPSS) group (positive control group), SCI model rats were treated with $100 \mathrm{mg} / \mathrm{kg}$ MPSS (i.p.); and iv) tocotrienol group, which experienced SCI and received $120 \mathrm{mg} / \mathrm{kg} /$ day tocotrienol once a day for eight consecutive weeks (15).

Evaluation of Basso Beattie Bresnahan (BBB) locomotor rating scale. The evaluation of locomotor function after treatment with tocotrienol on SCI was performed using the BBB locomotor rating scale of 0 (complete paralysis) to 21 (normal locomotion) (16).

Evaluation of the volume of spinal cord contusions after SCI. The volume of spinal cord contusions after SCI was evaluated by calculating as wet weight after treatment with doctrinal on SCI. Spinal cord tissue samples were dried at $80^{\circ} \mathrm{C}$ for $48 \mathrm{~h}$ and calculated as dry weight. The volume of spinal cord<smiles>CC(C)=CCC/C(C)=C/CC/C(C)=C/CC[C@]1(C)CCc2cc(O)c(C)c(C)c2O1</smiles>

Figure 1. Chemical structure of tocotrienol.

contusions was calculated by the following formula: Water content of spinal cord $(\%)=($ Wet weight-dry weight $) /$ wet weight $\mathrm{x} 100 \%$.

Evaluation of serum oxidative stress and inflammation. After the experimental administration of tocotrienol on SCI rats, serum was collected for analysis. Levels of MDA, SOD, CAT, GSH-PX, NF- $\kappa$ B p 65 unit, TNF- $\alpha$, IL-1 $\beta$ and IL-6 were analyzed using respective commercial immunoassay kits according to the manufacturers protocols (Wuhan Elabscience Biotechnology, Co., Ltd., Wuhan, China).

Western blot analysis. Spinal cord tissue samples $(50 \mathrm{mg})$ were homogenized in an ice-cold lysis buffer (Beyotime Institute of Biotechnology). The mixed liquor was centrifuged at $12,000 \times \mathrm{g}$ for $10 \mathrm{~min}$ at $4^{\circ} \mathrm{C}$. The supernatant was analyzed protein quantification using a bicinchoninic acid assay kit (catalog no. P0013B; Beyotime Institute of Biotechnology). Total proteins $(10 \mu \mathrm{g})$ were separated by electrophoresis using 10-12\% SDS-polyacrylamide gels and transferred onto nitrocellulose membranes (Merck Millipore). Membranes were washed with Tris buffer saline Tween-20 (TBST) three times and blocked with 5\% skim milk powder inTBST for $1 \mathrm{~h}$ at $37^{\circ} \mathrm{C}$. Subsequently, they were incubated using anti-iNOS (catalog no. sc-8310; 1:2,000), anti-TGF- $\beta$ (catalog no. sc-130348; 1:2,000), anti-collagen type IV (catalog no. sc-9301; 1:3,000), anti-fibronectin (catalog no. sc-69681; 1:4,000; Santa Cruz Biotechnology, Inc., Dallas, TX, USA) anti- $\beta$-actin (catalog no. D110007; 1:2,000; Sangon Biotech, Shanghai, China) primary antibodies at $4^{\circ} \mathrm{C}$ overnight. Then, membranes were incubated with horseradish peroxidase-conjugated goat anti-rabbit or anti-mouse secondary antibody (1:5,000; Santa Cruz Biotechnology, Inc.) at $37^{\circ} \mathrm{C}$ for $1 \mathrm{~h}$ and visualized using enhanced chemiluminescence agents (ECL Plus; Pierce Protein Biology; Thermo Fisher Scientific, Inc., Waltham, MA, USA). The optical densities of immunopositive bands were determined using Gene Tools analysis software (GeneTools, LLC, Philomath, OR, USA).

Determination of iNOS activity. Following experimentation, spinal cord tissues were collected from different groups. iNOS activity was determined using ELISA commercial kits according to the manufacturer instructions (catalog no. A014-1; Nanjing Jiancheng Bioengineering Institute).

Evaluation of plasma NO production. Following experimentation, the plasma supernatant was collected and underwent $12,000 \times \mathrm{g}$ centrifugation for $20 \mathrm{~min}$ at $4^{\circ} \mathrm{C}$. Nitrite concentration was determined using Griess reagent (1\% sulfanilamide and $0.1 \%$ naphthylethylenediamide in $5 \%$ phosphoric acid (Sangon Biotech) at a wavelength of $450 \mathrm{~nm}$ 


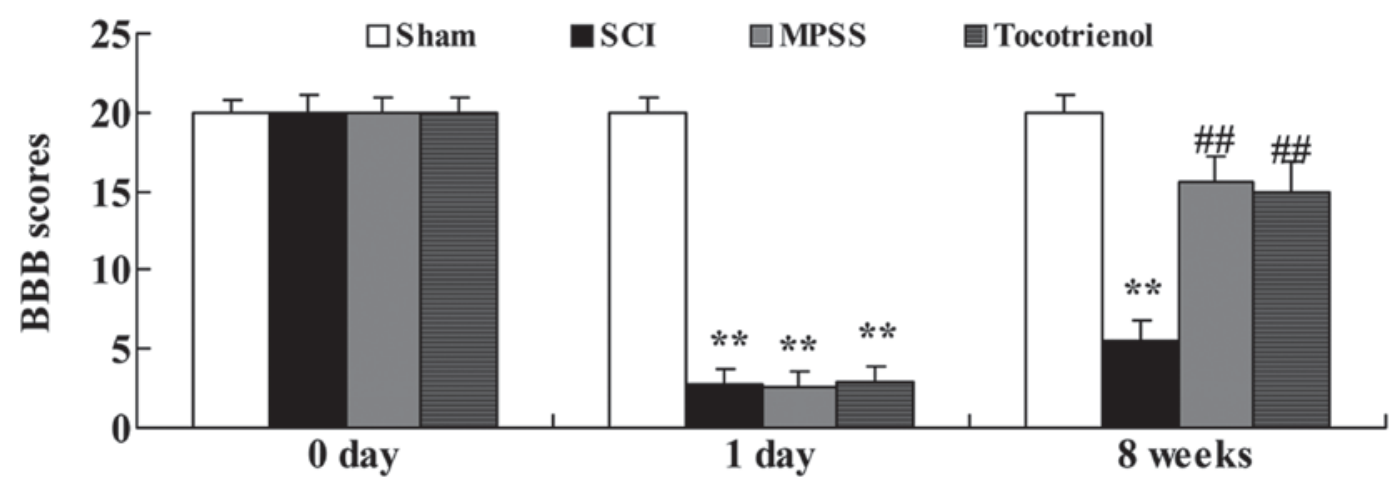

Figure 2. Effects of tocotrienol on functional recovery after $\mathrm{SCI}{ }^{* * *} \mathrm{P}<0.05$ vs. sham group; ${ }^{\# \#} \mathrm{P}<0.05$ vs. SCI group. Sham, Sham group; SCI, spinal cord injury group; MPSS, methylprednisolone-treated; Tocotrienol, tocotrienol (120 mg/kg)-treated.

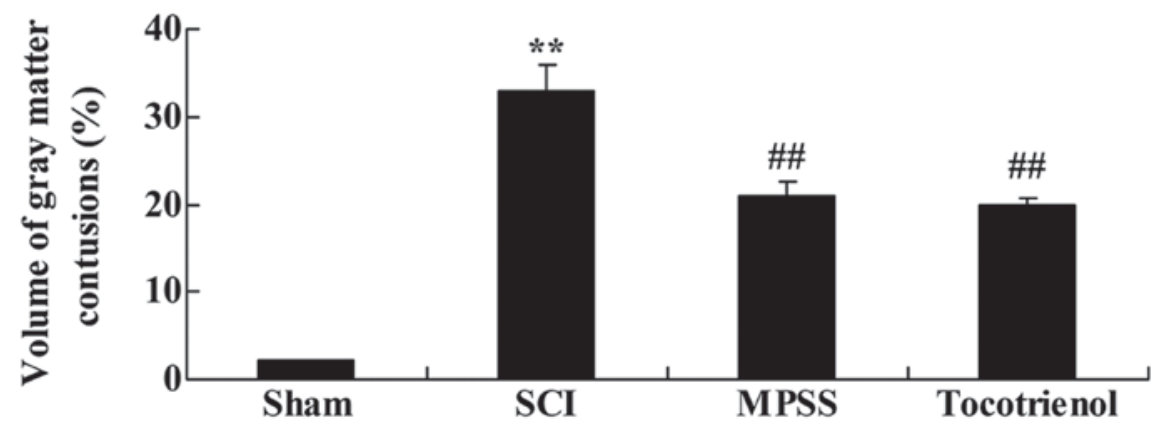

Figure 3. Effects of tocotrienol on the volume of gray matter contusions in the injured spinal cords. ${ }^{* *} \mathrm{P}<0.05$ vs. sham group; ${ }^{\# \#} \mathrm{P}<0.01 \mathrm{vs}$. SCI group. Sham, Sham group; SCI, spinal cord injury group; MPSS, methylprednisolone-treated; Tocotrienol, tocotrienol (120 mg/kg)-treated.

by a microplate reader (Bio-Rad Laboratories, Inc., Hercules, CA, USA).

Statistical analysis. Data are presented as the mean \pm standard deviation and analyzed using one-way analysis of variance followed by Dunnett's test. All statistical analyses were conducted using GraphPad Prism 5 (GraphPad Software, Inc., La Jolla, CA, USA). $\mathrm{P}<0.05$ was considered to indicate a statistically significant difference.

\section{Results}

Effect of tocotrienol on functional recovery after SCI. To assess the effects of tocotrienol on functional recovery after $\mathrm{SCI}$, functional recovery was assessed using BBB behavioral testing one day before SCI, one day post-SCI, and for eight weeks post-SCI. Reduced BBB scores were observed in SCI group at one day post-SCI or eight weeks post-SCI, compared to that of control group ( $\mathrm{P}<0.05$, Fig. 2$)$. At one day post-SCI, $\mathrm{BBB}$ scores were not significantly different in the MPSS or tocotrienol groups compared with the SCI group (Fig. 2). However, at eight weeks post-SCI, BBB scores were significantly higher in MPSS and tocotrienol groups compared with the SCI group ( $\mathrm{P}<0.05$, Fig. 2). There was no significant difference between MPSS and tocotrienol groups at any time point (P>0.05, Fig. 2).

Effect of tocotrienol on the volume of gray matter contusions in the injured spinal cords. Next, the effects of tocotrienol were investigated on the volume of gray matter contusions in the injured spinal cords. Contused volume was significantly increased in the SCI group, compared with the control group $(\mathrm{P}<0.05$, Fig. 3). Furthermore, contused volume was significantly reduced in the tocotrienol and MPSS groups compared with the SCI group $(\mathrm{P}<0.05$, Fig. 3). However, there was no significant difference between the MPSS and tocotrienol groups ( $\mathrm{P}>0.05$, Fig. 3).

Effect of tocotrienol on oxidative stress. To elucidate the effects of tocotrienol on oxidative stress in SCI rats, the serum levels of MDA, SOD, CAT and GSH-PX were evaluated. Initially, serum MDA levels were elevated and serum SOD, CAT and GSH-PX levels were suppressed in the SCI group compared with the control group $(\mathrm{P}<0.05$, Fig. 4). Furthermore, these SCI-induced changes in serum MDA, SOD, CAT and GSH-PX levels were significantly reversed by the MPSS and tocotrienol treatments, compared with the SCI group ( $\mathrm{P}<0.05$, Fig. 4). However, no significant inter-group difference was observed between the MPSS and tocotrienol groups for anti-oxidative effects in SCI model rats ( $\mathrm{P}>0.05$, Fig. 4).

Effect of tocotrienol on inflammation. To elucidate the effects of tocotrienols on inflammation of SCI rat, the serum levels of NF- $\kappa$ B p65 unit, TNF- $\alpha$, IL- $1 \beta$ and IL- 6 were evaluated. $\mathrm{SCI}$ induced inflammation reactions in rats, compared to the control group, as indicated by significantly elevated levels of the detected proteins $(\mathrm{P}<0.05$, Fig. 5). Notably, the serum NF- $\kappa \mathrm{B}$ p65 unit, TNF- $\alpha$, IL-1 $\beta$ and IL-6 levels were significantly 

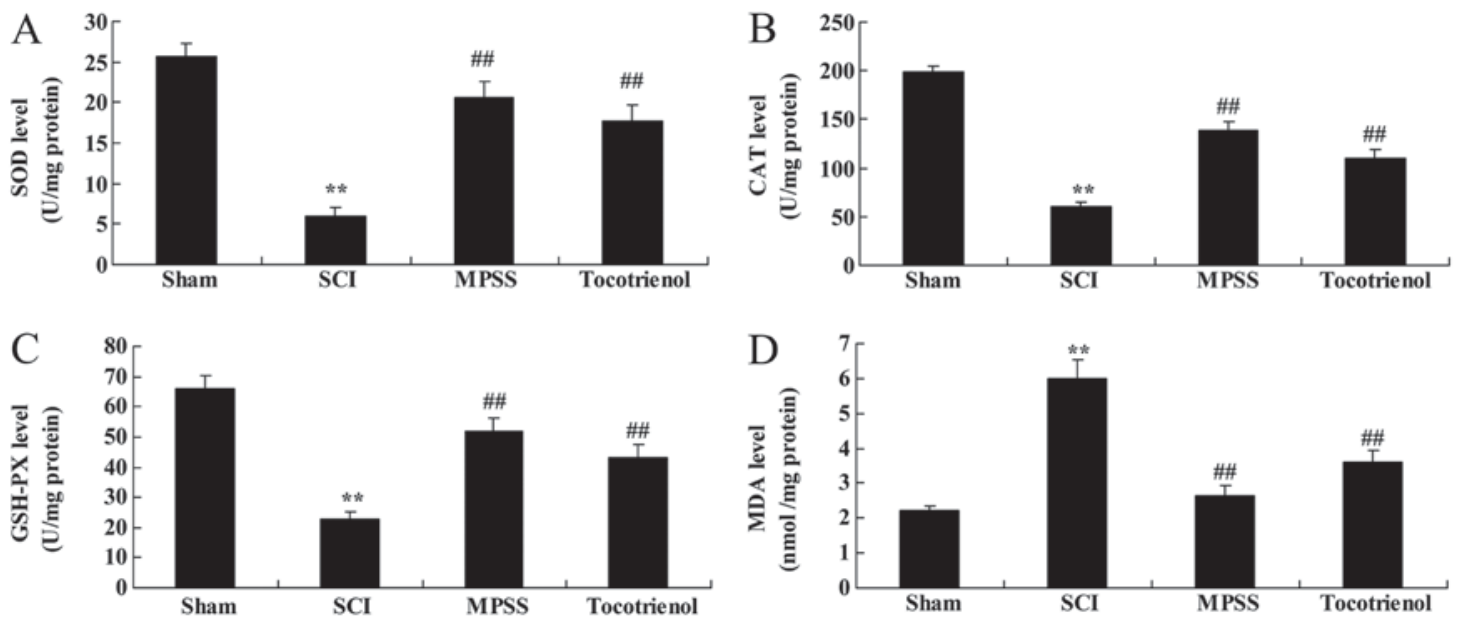

Figure 4. Effects of tocotrienol on oxidative stress. The effects of tocotrienol on (A) SOD, (B) CAT, (C) GSH-PX and (D) MDA levels in SCI rats. ${ }^{* *} \mathrm{P}<0.05$ vs. sham group; ${ }^{\# \#} \mathrm{P}<0.05$ vs. SCI group. Sham, Sham group; SCI, spinal cord injury group; MPSS, methylprednisolone-treated; Tocotrienol, tocotrienol $(120 \mathrm{mg} / \mathrm{kg})$-treated; SOD, superoxide dismutase; CAT, catalase; GSH-PX, glutathione peroxidase; MDA, malondialdehyde.
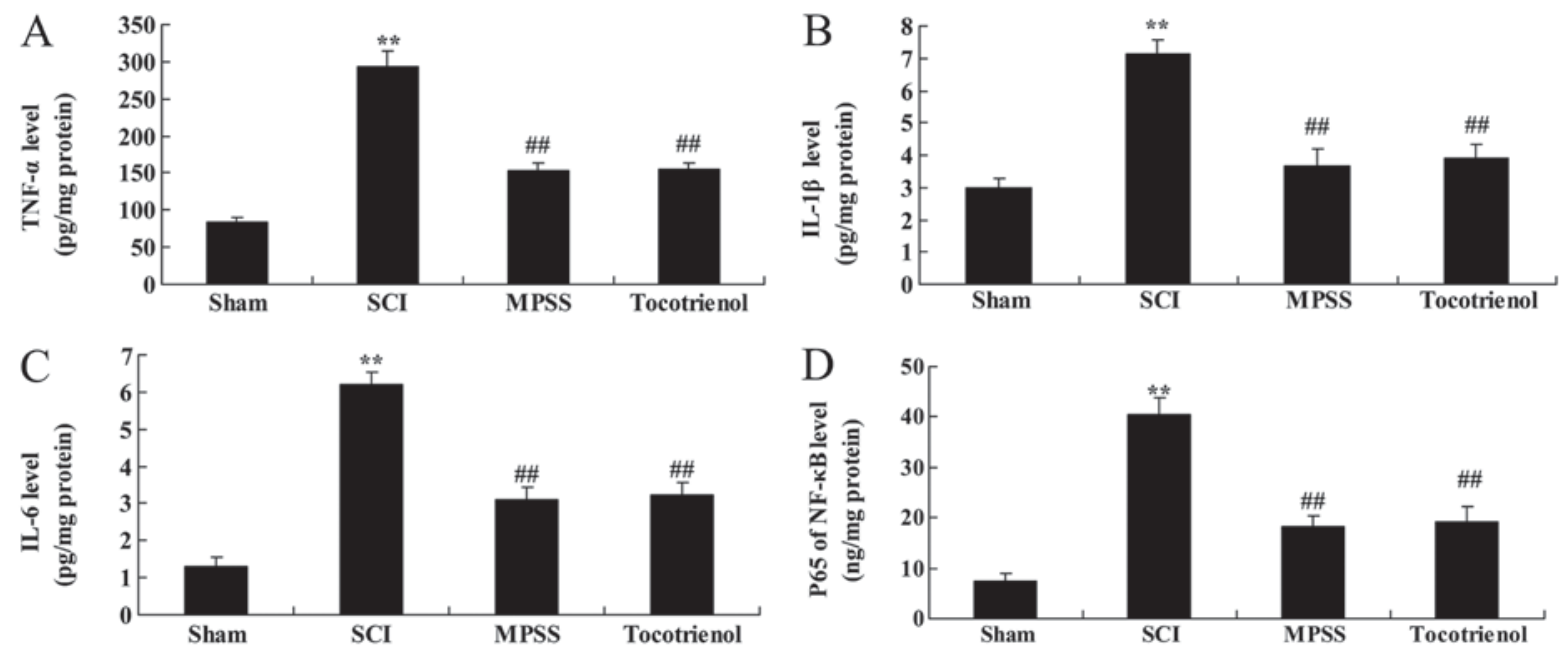

Figure 5. Effects of tocotrienol on inflammation. The effects of tocotrienol on (A) TNF- $\alpha$, (B) IL-1 $\beta$, (C) IL-6 and (D) NF- $\kappa B$ p65 unitin SCI rats. * P<0.05 vs. sham group; ${ }^{\# \#} \mathrm{P}<0.05$ vs. SCI group. Sham, Sham group; SCI, spinal cord injury group; MPSS, methylprednisolone-treated; Tocotrienol, tocotrienol $(120 \mathrm{mg} / \mathrm{kg})$-treated; TNF- $\alpha$, tumor necrosis factor- $\alpha$; IL-1 $\beta$, interleukin-1 $\beta$; IL-6, interleukin-6; NF- $\mathrm{kB}$ p65 unit, nuclear factor- $\mathrm{KB}$ p65 unit.

reduced by treatment with MPSS and tocotrienol, compared to theSCI group $(\mathrm{P}<0.05$, Fig. 5). However, no significant changes in the serum levels of NF- $\kappa$ B p65 unit, TNF- $\alpha$, IL- $1 \beta$ and IL-6 were detected between the MPSS and tocotrienol groups (P>0.05, Fig. 5A-D).

Effect of tocotrienol on iNOS expression, iNOS activity and plasma NO production. To explain the effects of tocotrienol on iNOS protein expression in SCI rats, iNOS protein expression, iNOS activity and plasma NO production were evaluated. SCI promoted iNOS protein expression in rats compared with the control group $(\mathrm{P}<0.05$, Fig. $6 \mathrm{~A}$ and $\mathrm{B})$. Treatment with MPSS and tocotrienol reduced iNOS protein expression compared to theSCI group $(\mathrm{P}<0.05$, Fig. 6A and $\mathrm{B})$. SCI activated iNOS activity and increased plasma NO production in SCI rats compared with the control group $(\mathrm{P}<0.05$, Fig. 6C and D). However, these changes were significantly reversed by treatment with MPSS and tocotrienol compared to the SCI group $(\mathrm{P}<0.05$, Fig. $6 \mathrm{C}$ and $\mathrm{D})$. Furthermore, no significant differences were detected in iNOS protein expression, iNOS activity and increased plasma NO production between the MPSS and tocotrienol groups ( $\mathrm{P}>0.05$, Fig. 6A-D).

Effect of tocotrienol on the expression of TGF- $\beta$. Western blot analysis was used to further elucidate the effects of tocotrienol on the expression of TGF- $\beta$ protein in SCI rats. Western blot analysis demonstrated that the expression of TGF- $\beta$ protein was significantly elevated in the SCI group compared with the sham group $(\mathrm{P}<0.05$, Fig. $7 \mathrm{~A}$ and $\mathrm{B})$. By contrast, treatment with MPSS and tocotrienol significantly inhibited TGF- $\beta$ protein expression, compared with the SCI group $(\mathrm{P}<0.05$, Fig. 7A and B). However, there was no significant difference between the MPSS and tocotrienol groups $(\mathrm{P}>0.05$, Fig. 7A and B).

Effect of tocotrienol on the expression of collagen type IV. Western blot analysis was used to evaluate the effects of tocotrienol on the protein expression levels of collagen type IV 

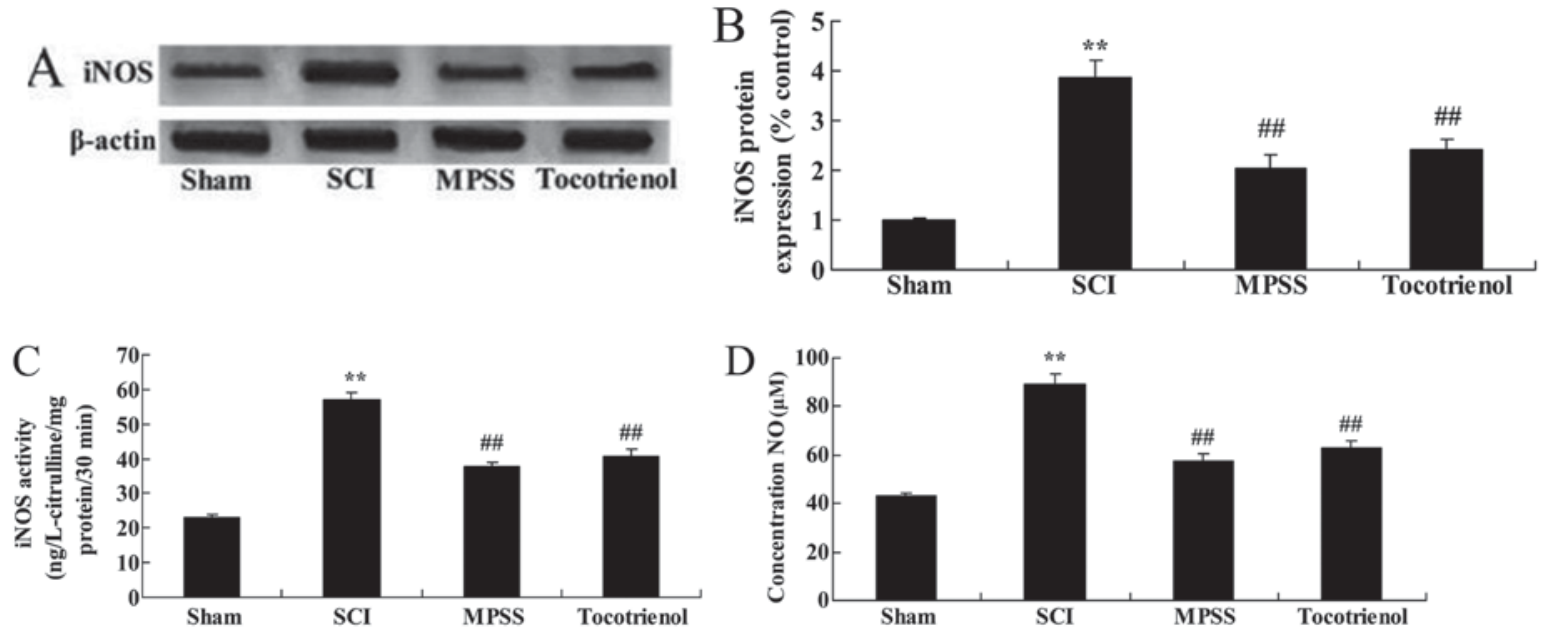

Figure 6. Effects of tocotrienol on iNOS expression, iNOS activity and plasma NO production. The effects of tocotrienol on iNOS protein expression by (A) western blot assays, and statistical analysis of (B) iNOS protein expression levels, (C) iNOS activity and (D) plasma NO production in SCI rats. ${ }^{* *} \mathrm{P}<0.05$ vs. sham group; ${ }^{\# \#} \mathrm{P}<0.05$ vs. SCI group. Sham, Sham group; SCI, spinal cord injury group; MPSS, methylprednisolone-treated; Tocotrienol tocotrienol $(120 \mathrm{mg} / \mathrm{kg})$-treated; iNOS, inducible nitric oxide synthase; NO, nitric oxide.

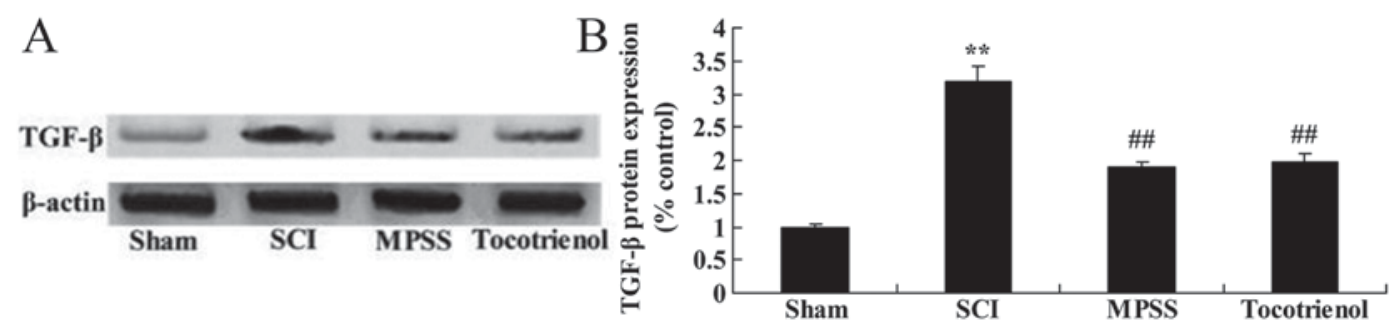

Figure 7. Effects of tocotrienol on the expression of TGF- $\beta$. The effects of tocotrienol on TGF- $\beta$ protein expression as showed by (A) western blot assay and (B) statistical analysis of TGF- $\beta$ protein expression levels in SCI rats. ${ }^{* *} \mathrm{P}<0.05$ vs. sham group; ${ }^{\# \#} \mathrm{P}<0.05$ vs. SCI group. Sham, Sham group; SCI, spinal cord injury group; MPSS, methylprednisolone-treated; Tocotrienol, tocotrienol (120 mg $/ \mathrm{kg})$-treated; TGF- $\beta$, transforming growth factor- $\beta$.

in SCI rats. The expression of collagen type IV protein was significantly increased in SCI model group, compared to the sham group $(\mathrm{P}<0.05$, Fig. $8 \mathrm{~A}$ and $\mathrm{B})$. However, MPSS and tocotrienol significantly reduced the collagen type IV protein expression compared with the SCI group $(\mathrm{P}<0.05$, Fig. 8A and B). However, there was no significant difference in collagen type IV protein expression between the MPSS and tocotrienol groups ( $\mathrm{P}>0.05$, Fig. $8 \mathrm{~A}$ and $\mathrm{B})$.

Effect of tocotrienol on the expression of fibronectin. Western blot analysis was used to further evaluate the effects of tocotrienol on the expression of fibronectin protein in SCI rats. As shown in Fig. 9A and B, there was a significant increase in fibronectin protein expression in the SCI model rats compared with the sham group. In contrast to the SCI model rats, MPSS and tocotrienol treatments significantly suppressed the protein expression of fibronectin $(\mathrm{P}<0.05$, Fig. 9A and B). However, in the expression no significant changes in fibronectin protein expression were detected between the MPSS and tocotrienol groups were observed ( $\mathrm{P}>0.05$, Fig. 9A and $\mathrm{B})$.

\section{Discussion}

As a result of the development of modern transportation and industrial and mining processes, SCI has become a commonly reported condition in clinical practice (14). The two damage mechanisms of primary and secondary SCI may combine to seriously affect human health and quality of life; potentially causing disabling injuries (14). Primary SCI occurs instantly after injury of spinal cord tissue due to exposure to external forces, and is an irreversible form of damage (17). On the basis of primary injury in the spinal cord tissue, the progressive, self-destructive cascade amplification destruction process caused by a variety of factors is known as secondary SCI; the degree of damage is substantially more than in primary SCI (17-19). The present study further showed that BBB scores and contused volume in rats post-SCI were improved and suppressed by treatment with tocotrienol, respectively. Frank et al (18) reported that tocotrienol has potential as a neuroprotective dietary factor.

Mitochondrial dysfunction is an important factor that causes the deaths of a large number of nerve cells following $\mathrm{SCI}$; this occurrence is directly associated with the accumulation of $\mathrm{Ca}^{2+}$ in the cell after the damage (20). Post-SCI oxidative stress damages the ion steady state inside and outside the mitochondrial membrane, $\mathrm{Ca}^{2+}$ accumulates inside the mitochondria, causing mitochondrial damage and aerobic energy metabolic disorders and inhibiting the synthesis of ATP (4). Following SCI, excessive activity of free radicals may be applied to the postsynaptic neuron, activating nearby astrocytes and microglia, causing ionic imbalance at the neuronal cell membrane (21). In addition, $\mathrm{Ca}^{2+}$-ATPase of the plasma 

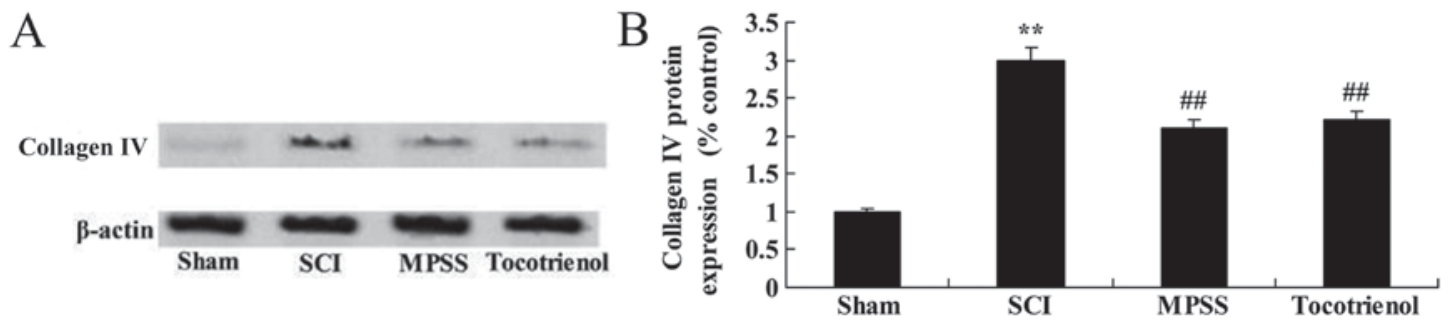

Figure 8. Effects of tocotrienol on the expression of collagen type IV. The effects of tocotrienol on collagen type IV protein expression by (A) western blot assay and (B) statistical analysis of collagen type IV protein expression levels in $\mathrm{SCI}$ rats. ${ }^{* *} \mathrm{P}<0.05$ vs. sham group; ${ }^{\# \#} \mathrm{P}<0.05$ vs. SCI group. Sham, Sham group; SCI, spinal cord injury group; MPSS, methylprednisolone-treated; Tocotrienol, tocotrienol (120 mg/kg)-treated.
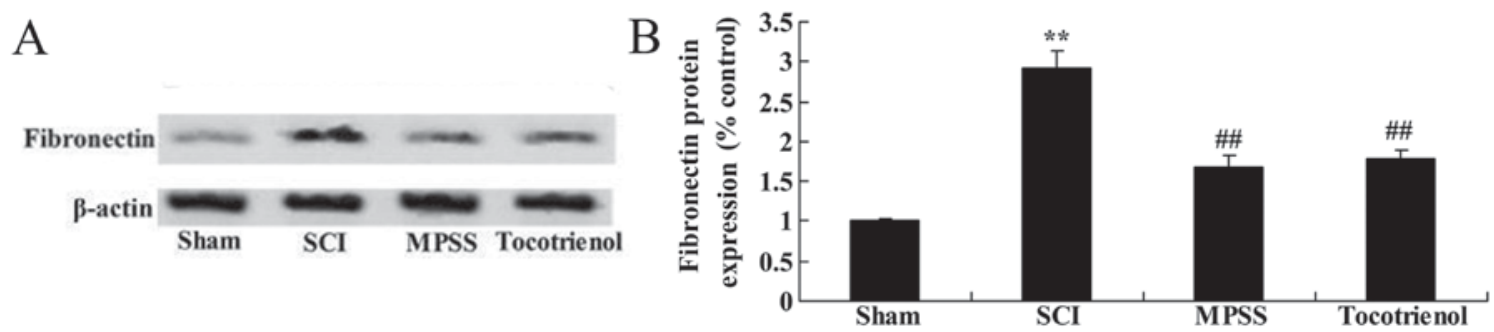

Figure 9. Effects of tocotrienol on the expression of fibronectin. The effects of tocotrienol on fibronectin protein expression by (A) western blot assay and (B) statistical analysis of fibronectin protein expression levels in SCI rats. ${ }^{* *} \mathrm{P}<0.05$ vs. Sham group; ${ }^{\# \#} \mathrm{P}<0.05$ vs. SCI group. Sham, Sham group; SCI, spinal cord injury group; MPSS, methylprednisolone-treated; Tocotrienol, tocotrienol (120 mg/kg)-treated.

and endoplasmic reticulum on the retina is highly sensitive to oxidative damage. Following SCI, the lipid peroxidation process can inhibit the activity of $\mathrm{Ca}^{2+}$-ATPase and interfere with the movement of $\mathrm{Ca}^{2+}$ out of the cell membrane, causing intracellular $\mathrm{Ca}^{2+}$ overload and ionic imbalance (4). The present results suggest that the neuroprotective effect of tocotrienol reduced the serum MDA level and increased the serum SOD, CAT and GSH-PX levels in SCI rats (21). Siddiqui et al showed that protective effects of tocotrienol may protect against nephropathy in experimental type- 2 diabetic rats by suppression of oxidative stress (21). Nizar et al (22) found that the antioxidative effect of tocotrienol protects osteoblasts through reduction of oxidative stress.

Inflammation serves a crucial function in the onset of SCI, inflammatory reaction of local damage tissue can increase the degree of secondary SCI (23). Following local damage, the secondary inflammatory environment may cause the injury of spinal cord cell necrosis and apoptosis, and irreversible pathological changes, thus aggravating SCI (24). Neutrophils may gather to the site of injury and release materials such as elastase; aggravating tissue edema, necrosis and promoting apoptosis of neurons and oligodendrocytes, and leading to local glial scar (24). The present findings support the protective effects of tocotrienol, which inhibited the serum levels of NF- $\kappa$ B p 65 unit, TNF- $\alpha$, IL-1 $\beta$ and IL-6 in SCI rats. González et al (25) indicated that tocotrienols exhibit anti-inflammatory properties and protect from arginine chronic-like pancreatitis. Yam et al (26) suggested that tocotrienols suppress proinflammatory markers in RAW264.7 macrophages.

Numerous studies have shown that central nerve damage caused by ischemia and trauma can lead to substantial and persistent expression of neuronal iNOS, and synthesis of excessive quantities of NO, which has direct neurotoxic effects (27). NO is a type of small molecular free radical with a wide range of biological activity, including vasodilation, nerve information transfer and cytotoxic effects (27). NO and iNOS are crucially involved in central nervous system injury. Excessive NO can induce cell apoptosis, and apoptosis is believed to be important factor of SCI secondary change (28). The present results showed that the protective effects of tocotrienol reduced iNOS protein expression, iNOS activity and plasma NO production in SCI rats. Qureshi et al reported that tocotrienol inhibits lipopolysaccharide-induced proinflammatory cytokines through suppression of iNOS gene expression in macrophages of female mice (29).

The positive expression of TGF- $\beta$ is visualized as red granular staining in the cytoplasm of articular cartilage in rats (30). The expression level of TGF- $\beta$ in rats with cartilage articular is is relatively low except that the expression on the surface of the articular cartilage is significantly higher than that of the middle and deep layer of cartilage (31). It has been previously reported that TGF- $\beta 1,-\beta 2$ and $-\beta 3$ are strongly expressed on the surface layer, transitional layer and the low-maturity cell layer of cartilage cells during the process of chondrogenesis (30). Experiments have confirmed that TGF- $\beta$ is expressed in the early stage of cartilage formation, in cartilage callus mesenchymal cells, immature chondrocytes and mature chondrocytes (32). Furthermore, previous studies show that the extracellular expression of TGF- $\beta 1$ initially appeared in the hematoma in injured area after the spinal cord injury, and the expression is subsequently enhanced in the cytoplasm and nucleus of astrocytes, intramedullary and extramedullary capillary endothelial cells and motor neurons $(33,34)$. The present results indicate that treatment with tocotrienols significantly inhibited TGF- $\beta$ protein expression in SCI rats. Siddiqui et al (21) reported that tocotrienol mitigates the damage of lipid-induced nephropathy through suppression of TGF- $\beta$ and collagen type IV. 
Fibronectin is a multifunctional glycoprotein found in the extracellular matrix and plasma (35). Widely existing in animal tissues and tissue fluid, fibronectin is a V-shaped macromolecular glycoprotein with a molecular weight of $\sim 450 \mathrm{kDa}$ and a variety of biological activities (36). Numerous international studies have shown that the fibronectin molecule is highly conserved in the evolution process, and various animal body fluids share similar structure, properties and biological function, therefore, fibronectin from different organisms may be interchangeable $(33,34,37)$. Fibronectin has many different subunits which are the expression products of the same gene but different in the RNA splicing after transcription and thus different mRNA are produced (38). Fibronectin is widely distributed in hematoma, the surface of numerous types of cells and extracellular matrix (36). Fibronectin is crucially involved in cell adhesion, migration, differentiation and functions. In recent years, fibronectin has been found to play an important role in the occurrence and development of arthritis and cartilage degeneration (39). In the present study, tocotrienol treatment significantly reduced the collagen type IV and fibronectin protein expression levels of SCI rats. González et al reported that tocotrienol prevents against lipid-induced nephropathy through suppression of TGF- $\beta$ and collagen type IV (25).

SCI can directly cause necrosis and apoptosis of vascular endothelial cells, basement membrane components and structural damage of the microvascular wall, which are contributed to the disruption of the blood-spinal cord barrier and lead to the leakage of vascular material, and further aggravate the inflammatory reaction, edema and other secondary injury (40). As the basement membrane component, collagen IV and laminin begin degradation following spinal cord injury; however, the secretion of collagen IV and laminin are enhanced accordingly as the mechanism of vascular regeneration is activated rapidly by pathophysiological requirements (41). Previous results have shown that the early formation of collagen IV and laminin after spinal cord injury contribute to the restriction of inflammatory reaction and the promotion of neovascularization $(40,41)$. Furthermore, pretreatment with tocotrienol treatment significantly reduced the protein expression of fibronectin in SCI rats, in the present study. González et al (25) reported that oral tocotrienols improve quantitative measures of chronic pancreatic damage through fibronectin.

In conclusion, tocotrienol attenuated the functional recovery and the volume of gray matter contusions of SCI rats. Prevention of oxidative damage, inflammation and iNOS may be the key mechanisms underlying the effect of tocotrienol on SCI through collagen type IV and fibronectin, thereby promoting functional recovery in SCI rats, potentially in part via the TGF- $\beta$ signaling pathway.

\section{References}

1. Rosado IR, Lavor MS, Alves EG, Fukushima FB, Oliveira KM, Silva CM, Caldeira FM, Costa PM and Melo EG: Effects of methylprednisolone, dantrolene, and their combination on experimental spinal cord injury. Int J Clin Exp Pathol 7: 4617-4626, 2014.

2. Song Q, Xu R, Zhang Q, Ma M and Zhao X: Therapeutic effect of transplanting bone mesenchymal stem cells on the hind limbs motor function of rats with acute spinal cord injury. Int J Clin Exp Med 7: 262-267, 2014.
3. Liu C, Huang Z, Jiang H and Shi F: The sirtuin 3 expression profile is associated with pathological and clinical outcomes in colon cancer patients. Biomed Res Int 2014: 871263, 2014.

4. Guo J, Li Y, He Z, Zhang B, Li Y, Hu J, Han M, Xu Y, Li Y, $\mathrm{Gu}$ J, et al: Targeting endothelin receptors $\mathrm{A}$ and $\mathrm{B}$ attenuates the inflammatory response and improves locomotor function following spinal cord injury in mice. Int J Mol Med 34: 74-82, 2014.

5. Grasso G, Meli F, Graziano F, Stagno V, Imbrucè P, Florena AM, Maugeri R and Iacopino DG: Chronic inflammation causing spinal cord compression in human immunodeficiency virus infection. Med Sci Monit 14: CS134-CS137, 2008.

6. Ji H, Tang H, Lin H, Mao J, Gao L, Liu J and Wu T: Rho/Rock cross-talks with transforming growth factor- $\beta /$ Smad pathway participates in lung fibroblast-myofibroblast differentiation. Biomed Rep 2: 787-792, 2014.

7. $\mathrm{Yu} \mathrm{Z}, \mathrm{Yu} \mathrm{P}$, Chen $\mathrm{H}$ and Geller HM: Targeted inhibition of KCa3.1 attenuates TGF- $\beta$-induced reactive astrogliosis through the Smad2/3 signaling pathway. J Neurochem 130: 41-49, 2014.

8. Banh A, Deschamps PA, Gauldie J, Overbeek PA, Sivak JG and West-Mays JA: Lens-specific expression of TGF-beta induces anterior subcapsular cataract formation in the absence of Smad3. Invest Ophthalmol Vis Sci 47: 3450-3460, 2006.

9. Loganathan R, Selvaduray KR, Nesaretnam K and Radhakrishnan AK: Tocotrienols promote apoptosis in human breast cancer cells by inducing poly(ADP-ribose) polymerase cleavage and inhibiting nuclear factor kappa-B activity. Cell Prolif 46: 203-213, 2013.

10. Das S, Mukherjee S, Lekli I, Gurusamy N, Bardhan J, Raychoudhury U, Chakravarty R, Banerji S, Knowlton AA and Das DK: Tocotrienols confer resistance to ischemia in hypercholesterolemic hearts: Insight with genomics. Mol Cell Biochem 360: 35-45, 2012.

11. Zarogoulidis P, Cheva A, Zarampouka K, Huang H, Li C, Huang Y, Katsikogiannis N and Zarogoulidis K: Tocopherols and tocotrienols as anticancer treatment for lung cancer: Future nutrition. J Thorac Dis 5: 349-352, 2013.

12. Tanito M, Itoh N, Yoshida Y, Hayakawa M, Ohira A and Niki E: Distribution of tocopherols and tocotrienols to rat ocular tissues after topical ophthalmic administration. Lipids 39: 469-474, 2004.

13. Sylvester PW, Akl MR, Malaviya A, Parajuli P, Ananthula S, Tiwari RV and Ayoub NM: Potential role of tocotrienols in the treatment and prevention of breast cancer. Biofactors 40: 49-58, 2014.

14. Zhang X, Chen C, Ma S, Wang Y, Zhang X and Su X: Inhibition of monocyte chemoattractant peptide-1 decreases secondary spinal cord injury. Mol Med Rep 11: 4262-4266, 2015.

15. Wong WY, Poudyal H, Ward LC and Brown L: Tocotrienols reverse cardiovascular, metabolic and liver changes in high carbohydrate, high fat diet-fed rats. Nutrients 4: 1527-1541, 2012.

16. Basso DM, Beattie MS, Bresnahan JC, Anderson DK, Faden AI, Gruner JA, Holford TR, Hsu CY, Noble LJ, Nockels R, et al: MASCIS evaluation of open field locomotor scores: Effects of experience and teamwork on reliability. Multicenter Animal Spinal Cord Injury Study. J Neurotrauma 13: 343-359, 1996.

17. Genovese T, Esposito E, Mazzon E, Muià C, Di Paola R, Meli R, Bramanti P and Cuzzocrea S: Evidence for the role of mitogen-activated protein kinase signaling pathways in the development of spinal cord injury. J Pharmacol Exp Ther 325: 100-114, 2008

18. Frank J, Chin XW, Schrader C, Eckert GP and Rimbach G: Do tocotrienols have potential as neuroprotective dietary factors? Ageing Res Rev 11: 163-180, 2012.

19. Ahsan H, Ahad A, Iqbal J and Siddiqui WA: Pharmacological potential of tocotrienols: A review. Nutr Metab (Lond) 11: 52, 2014.

20. Bao F, Chen Y, Schneider KA and Weaver LC: An integrin inhibiting molecule decreases oxidative damage and improves neurological function after spinal cord injury. Exp Neurol 214: 160-167, 2008.

21. Siddiqui S, Ahsan H, Khan MR and Siddiqui WA: Protective effects of tocotrienols against lipid-induced nephropathy in experimental type- 2 diabetic rats by modulation in TGF- $\beta$ expression. Toxicol Appl Pharmacol 273: 314-324, 2013.

22. Nizar AM, Nazrun AS, Norazlina M, Norliza M and Ima Nirwana S: Low dose of tocotrienols protects osteoblasts against oxidative stress. Clin Ter 162: 533-538, 2011

23. Sribnick EA, Wingrave JM, Matzelle DD, Wilford GG, Ray SK and Banik NL: Estrogen attenuated markers of inflammation and decreased lesion volume in acute spinal cord injury in rats. J Neurosci Res 82: 283-293, 2005. 
24. Tamai H, Sawamura S, Takeda K, Orii R and Hanaoka K: Anti-allodynic and anti-hyperalgesic effects of nociceptin receptor antagonist, JTC-801, in rats after spinal nerve injury and inflammation. Eur J Pharmacol 510: 223-228, 2005.

25. González AM, Garcia T, Samper E, Rickmann M, Vaquero EC and Molero X: Assessment of the protective effects of oral tocotrienols in arginine chronic-like pancreatitis. Am J Physiol Gastrointest Liver Physiol 301: G846-G855, 2011.

26. Yam ML, Abdul Hafid SR, Cheng HM and Nesaretnam K: Tocotrienols suppress proinflammatory markers and cyclooxygenase-2 expression in RAW264.7 macrophages. Lipids 44: 787-797, 2009.

27. Chen G, Zhang Z, Wang S and Lv D: Combined treatment with FK506 and nerve growth factor for spinal cord injury in rats. Exp Ther Med 6: 868-872, 2013.

28. Liu C, Wu W, Zhang B, Xiang J and Zou J: Temporospatial expression and cellular localization of glutamine synthetase following traumatic spinal cord injury in adult rats. Mol Med Rep 7: 1431-1436, 2013.

29. Qureshi AA, Reis JC, Papasian CJ, Morrison DC and Qureshi N: Tocotrienols inhibit lipopolysaccharide-induced pro-inflammatory cytokines in macrophages of female mice. Lipids Health Dis 9: 143, 2010

30. Wang X, Chen W, Liu W, Wu J, Shao Y and Zhang X: The role of thrombospondin-1 and transforming growth factor-beta after spinal cord injury in the rat. J Clin Neurosci 16: 818-821, 2009.

31. Park SM, Jung JS, Jang MS, Kang KS and Kang SK Transforming growth factor-betal regulates the fate of cultured spinal cord-derived neural progenitor cells. Cell Prolif 41: 248-264, 2008.

32. Andrew JG, Hoyland J, Andrew SM, Freemont AJ and Marsh D: Demonstration of TGF-beta 1 mRNA by in situ hybridization in normal human fracture healing. Calcif Tissue Int 52: 74-78, 1993.
33. Gensel JC and Zhang B: Macrophage activation and its role in repair and pathology after spinal cord injury. Brain Res 1619: 1-11, 2015.

34. Kandasamy M, Lehner B, Kraus S, Sander PR, Marschallinger J, Rivera FJ, Trümbach D, Ueberham U, Reitsamer HA, Strauss O, et al: TGF-beta signalling in the adult neurogenic niche promotes stem cell quiescence as well as generation of new neurons. J Cell Mol Med 18: 1444-1459, 2014.

35. Bachman H, Nicosia J, Dysart M and Barker TH: Utilizing fibronectin integrin-binding specificity to control cellular responses. Adv Wound Care (New Rochelle) 4: 501-511, 2015.

36. Zhu Y, Soderblom C, Trojanowsky M, Lee DH and Lee JK: Fibronectin matrix assembly after spinal cord injury. J Neurotrauma 32: 1158-1167, 2015.

37. Xia M and Zhu Y: Fibronectin enhances spinal cord astrocyte proliferation by elevating P2Y1 receptor expression. J Neurosci Res 92: 1078-1090, 2014.

38. King VR, Hewazy D, Alovskaya A, Phillips JB, Brown RA and Priestley JV: The neuroprotective effects of fibronectin mats and fibronectin peptides following spinal cord injury in the rat. Neuroscience 168: 523-530, 2010.

39. Xia M: Fibronectin blocks the recovery of spinal cord injury by increasing P2Y1 receptor level. Int J Dev Neurosci 47: 20-21, 2015.

40. Koopmans G, Hasse B and Sinis N: Chapter 19: The role of collagen in peripheral nerve repair. Int Rev Neurobiol 87: 363-379, 2009

41. Liesi P and Kauppila T: Induction of type IV collagen and other basement-membrane-associated proteins after spinal cord injury of the adult rat may participate in formation of the glial scar. Exp Neurol 173: 31-45, 2002. 